УДК $811.111: 81.373 .46$

DOI https://doi.org/10.26661/2414-1135-2021-84-35

\title{
АНГЛОМОВНА КОМП'ЮТЕРНА ТЕРМІНОЛОГІЯ: СТРУКТУРНІ ОСОБЛИВОСТІ ТА СПОСОБИ ТВОРЕННЯ
}

\author{
Фесенко I. М. \\ кандидат філологічних наук, доиент, \\ дочент кафедри теорії та практики перекладу з англійської мови \\ Запорізький національний університет \\ вул. Жуковського, 66, Запоріжжя, Украӥна \\ orcid.org/0000-0002-0995-6258 \\ irina.fesenko@gmail.com
}

Сивачук О. М.

старший викладач кафедри іноземних мов

Національний університет «Запорізька політехніка»

вул. Жуковського, 64, Запоріжжя, Украӥна

orcid.org/0000-0002-9747-0070

elena.syvachuk@gmail.com

Ключові слова: комп 'ютерний термін, прості терміни, складні терміни, скорочення, афіксачія, суфіксація.
Стаття присвячена розгляду структурно-семантичних особливостей комп'ютерних термінів сучасної англійської мови й основних способів їх творення. На текучість комп'ютерної лексики впливають декілька чинників: науково-технічний прогрес, іманентна тенденція комп'ютерної лексики до швидкого оновлення, зміна актуальних тем для обговорення. На початку XXI століття постіндустріальна цивілізація вступила в еру електроніки й інформатики. Інтернет привів до революції в системах комунікації. Персональний комп'ютер став невід'ємною частиною роботи і відпочинку. Розвиток нової галузі знання приводить до розвитку та систематизації спеціальної термінології. У зв'язку із цим особливого значення набувають дослідження, спрямовані на виявлення специфіки комп'ютерної термінології, вивчення однісї із професійних підмов підмови комп'ютерних технологій, що найбільш динамічно розвивається. У процесі дослідження було зроблено такі висновки. Термін є самостійною єдиною одиницею найменування, якій притаманна складна внутрішня семантична структура. Термін має спеціальне термінологічне значення, яке відображає основні, суттєві на даному етапі розвитку науки і техніки, ознаки певного поняття.

Варто зауважити, що для створення термінів здавна використовуються відомі способи, серед основних такі: конверсія, словоскладання, афіксація, скорочення, телескопія. У досліджуваній терміносистемі більшість термінів утворені афіксальним способом.

Прості терміни утворюються за допомогою суфіксації та префіксації. Терміни - складні слова проникають в англійську мову, оскільки значення складного слова завжди більш точне, ніж значення словосполучення. Серед термінів-словосполучень поширені поєднання іменника iз прикметником, іменника 3 іменником у непрямому відмінку. Існують терміни-словосполучення, компонентами яких є самостійні слова, які можуть уживатись окремо, терміни-словосполучення, у яких один із компонентів - технічний термін, а другий - слово загальновживаної лексики, терміни-словосполучення, утворені на основі наявних у мові слів із новим значенням. 


\title{
COMPUTER TERMINOLOGY OF THE ENGLISH LANGUAGE: STRUCTURAL PECULIARITIES AND WAYS OF FORMATION
}

\author{
Fesenko I. M. \\ Candidate of Philological Sciences, Associate Professor, \\ Associate Professor at the Department of English Translation Theory and Practice \\ Zaporizhzhia National University \\ Zhukovskoho str., 66, Zaporizhzhia, Ukraine \\ orcid.org/0000-0002-0995-6258 \\ irina.fesenko@gmail.com
}

Syvachuk O. M.

Senior Lecturer at the Department of Foreign Languages

"Zaporizhzhia Polytechnic" National University

Zhukovskoho str., 64, Zaporizhzhia, Ukraine

orcid.org/0000-0002-9747-0070

elena.syvachuk@gmail.com

Key words: computer term, simple terms, compound terms, abbreviation, affixation, suffixation.
The article is devoted to the study of the computer terms in the English language: their structural peculiarities and the main ways of word formation. Terms are words that perform a particular function. Scientists reason the function of term in different ways. Some scientists believe that they perform the nominative function, others - the descriptive one. It is believed that terms perform both functions. Terms as words possess significative, communicative, grammatical features and functions.

Simple terms are made by means of suffixation and prefixation. Termscompound words penetrate English because the meaning of a compound word is always more accurate than the value of the phrase. Among terms-wordcombinations, combinations of noun and adjectives, of nouns and nouns in the objective case are common. There are terms-phrases, components of which are words that can be used separately; terms-word-combinations, where one of the components is the technical term, and the second is from the common lexicon; and terms formed based on the words, existing in the language, but with new meanings.

For the correct understanding of computer terms, it is necessary to know their morphological structure, semantic features that distinguish them from common words, contextual features of functioning of these units. Among the most productive ways of formation of computer terms are suffixes: -wise, -ment, -able, -itis, -ation; half-suffixes: -ware, -speak; and prefixes: cyber-, e-, net-, re-, non-, anti-, as-. It can also be said that convertible terms, both substantivized and verbalized, are common. Another most productive way of term-formation is abbreviation (acronyms), with the help of which the parts of computers and new software are described. Telescopic nomination is also worth mentioning as it accounts for a great number of computer terms in the English language. In telescopic terms the fragment of the first word forms the second fragment of the word, and whole word forms the whole word or whole word forms a fragment of a word.
Лексика комп'ютерних технологій 3'явилась відносно нещодавно, нині стрімко поповнюється і вдосконалюється, відображує процеси ускладнення модернізації в галузі комп’ютерів та інформаційних систем. Динаміка розвитку цієї сфери зумовлює такі ж динамічні процеси і в термінології, як-от: застаріння одних термінів, поява безлічі інших, синонімія термінів, варіативність термінологічних одиниць. Питання впорядкування термінів комп'ютерної сфери за 
визначеними параметрами залишається маловивченим.

Мета статті - надати класифікацію англомовних комп'ютерних термінів, з урахуванням їхніх структурно-семантичних особливостей, а також навести основні моделі їх перекладу українською мовою.

Об'єктом наукової статті є структурні особливості та способи творення комп'ютерної термінології.

Предметом дослідження статті є комп'ютерна термінологія англійської мови. Матеріалом дослідження даної роботи послужила вибірка одиниць комп'ютерної термінології з комп'ютерних журналів, книжок та інтернет-сайтів.

Для досягнення мети ми маємо виконати такі завдання: 1) розглянути різні підходи до визначення терміна в системі мови, надати більш вичерпне визначення комп'ютерних термінів сучасної англійської мови, зважаючи на їхні структурні особливості та словотворчі потенції; 2) навести основні структурно-семантичні способи творення англомовних комп'ютерних термінів.

Що стосується перспектив подальшого дослідження комп'ютерних термінів, то вони полягають у вивченні проблеми «точності» передачі значення під час перекладу такого роду термінів, особливо неологізмів, кількість яких постійно збільшується, не встигаючи знайти адекватний переклад у спеціальних словниках. Перспективною буде також подальша робота над проблемами термінології, серед яких вивчення частотності й особливостей уживання спеціальної лексики в різних типах текстів за рівнем їхньої специфікації - у суто наукових або науково-популярних. Тому стаття $є$ стислим викладом досліджень функціонування термінології у сфері комп'ютерних технологій.

Актуальність статті зумовлена лінгвістичними й екстралінгвістичними чинниками, які впливають на появу та функціонування комп'ютерних термінів.

У першій половині 20-го століття ні лінгвісти, ні соціологи не приділяли особливу увагу термінології. Тож, такою, як ми іiі розуміємо нині, вона почала формуватися в 1930-і рр. Роботи О. Вюстера, австрійського лінгвіста та засновника термінологіï, були дуже важливими для іiі сучасного розвитку. О. Вюстер розробив свою концепцію сукупності термінів, спираючись на свій досвід роботи інженером, брав участь у національній та міжнародній стандартизації термінології, що є необхідним для ефективного впровадження стандартизації фізичних об’єктів, процедур і вимірювань у різних галузях техніки [1, с. 167]. Загальна мета його справи полягає у створенні символічних одиниць через асоціацію наукових або технічних концепцій, їхня перевага полягає в забезпеченні однозначності у професійному спілкуванні, особливо на міжнародному рівні [2].

Натепер налічується більше 3000 визначень поняття «термін», проте його зміст не з'ясовано до кінця. Зазвичай фахівці користуються робочими визначеннями терміна, які неповні, однак відображають його істотні властивості, як приклад наведемо визначення Г. Винокура: «У ролі терміна може виступати будь-яке слово < ..> термін - це не особливе слово, а тільки слово в особливій функції, функції найменування спеціального поняття, назви спеціального предмета або явища» $[3$, с. 5$]$.

Інший учений, П. Фабер, дає таке визначення терміна: «терміни - це мовні одиниці, які передають концептуальне значення в рамках спеціалізованих текстів знань» [4, с. 109]. А. Реформатський визначає терміни як «однозначні слова, позбавлені експресивності» [5]. М. Глушко констатує, що «термін - це слово чи словосполучення для вираження понять і позначення предметів, що володіє, завдяки наявності в нього суворої і точної дефініції, чіткими семантичними кордонами, тому однозначне в межах відповідної класифікаційної системи» [6, с. 33].

Основна вимога до терміна - його однозначність. У загальнотермінологічному плані ця вимога реалізується двома шляхами, оскільки є дві категорії термінів: 1) загальнонаукові та загальнотехнічні терміни; 2) спеціальні (номенклатурні) терміни. Загальнонаукові та загальнотехнічні терміни виражають загальні поняття науки і техніки. Терміни існують не просто в мові, а у складі певної термінології. Термінологія, як система наукових термінів, є підсистемою всередині загальної лексичної системи мови [7, с. 151]. Згідно з А. Реформатським, термінологія - це система понять даної науки, закріплених у відповідному словесному вираженні [5]. Якщо в загальній мові (поза даною термінологією) слово може бути багатозначним, то коли воно потрапляє в якусь термінологію, то набуває однозначності.

Одиницями комп'ютерної терміносистеми $є$ терміни-слова або словосполучення, які мають спеціальне, суворо визначене значення в окремій (у нашому випадку комп'ютерній) галузі [8, с. 88].

Комп'ютерні терміни в англійській мові за структурою поділяються на прості терміни, складні та терміни-словосполучення. Прості комп'ютерні терміни утворюються головним чином за допомогою суфіксації і префіксації.

Так, наприклад, за допомогою суфіксів -er, -or, -ist утворюються іменники, що позначають працівника-фахівця: programmer, provider, administrator; а також машини, інструменти, прилади: adapter, computer, server, scanner. 
Іменники 3 конкретним предметним значенням утворюються за допомогою суфіксів -ing, -ment: tracking, hosting, development.

Суфікс -ing використовується для позначення технологічних процесів і дії взагалі: morphing, resampling, zooming.

Суфікс -(t)ion використовується для вираження дії: composition, classification, addition, acceleration, activation.

У системі термінотворення широко застосовується суфікс прикметника -wise, що надає основі значення «у напрямку, паралельно»: streamwise, slantwise.

Розроблені спеціальні правила утворення термінів для понять або об'єктів певного класу. Так, назва програмного забезпечення створюється за аналогією 3 терміном hard-ware: software, freeware, radware.

Відзначимо, що однослівні терміни неоднорідні за кількістю словотворчих компонентів. Відповідно до цієї основи однослівні терміни поділяють на такі групи:

- у структуру терміна входить одна основа: agent: "Tell the agent what you want done, set it free, and wait for it to return results sounds too good to be true" (Communications of the Association for Information Systems, August, 2004 p.); byte: "A conventional signature usually contains a series of bytes that envoy a specific attack" (International Journal on Computer Science and Engineering, March, 2012 p.); domain: "Focused crawler collects domain relevant pages from the Web by avoiding the irrelevant portion of the Web" (International Journal of Computer Applications, April, 2012 p.); entity; filter: "The proposed filtering technique of impulse detection followed by ATM filter is capable of producing high quality images and it prevents image blurring compared to other denoising techniques" (International Journal of Computer Applications, April, 2012 p.); host: "Network Compromise Percentage (NCP) is defined as a percentage of hosts in network which accessed by attacker using user or administrator access level" (Journal of Global Research in Computer Science, March, 2012 p.); net; port: "The six port junction consists of two input ports and four output ports" ("International Journal of Computer Applications", April, 2012 p.); tag: "With only two tag SNPs, the prediction accuracy of the proposed method reached 97\% and was generally much higher than that obtained by the other methods" (Lecture Notes in Engineering and Computer Science, March, 2012 p.); traffic: "Fine-tuning, analyzing and optimizing voice traffic over data networks have been a major challenge to researchers and developers, many techniques have been proposed based on analyses from real word and simulated traffic" (World of Computer Science and Information Technology Journal, May, 2012 p.);
- структуру терміна становлять основа й один і більше афіксів: acknowledgement, application, archive, multicast, multimedia.

Складні терміни можуть уживатися в одній терміносистемі, але мати різні значення залежно від контексту.

Термін - складне слово - це найчастіше поєднання двох або більше основ іменників, які збігаються за формами та наводяться у словниках. Термінологічно стійке словосполучення зазвичай утворюється поєднанням прикметника 3 іменником, дієприкметника 3 іменником або кількох іменників: binary data, binary digit, chaining search.

Терміни - складні слова все більше проникають в англійську науково-технічну літературу, оскільки значення складного слова завжди більш точно спеціалізоване, ніж значення відповідного словосполучення, наприклад складне слово denial-of-service attack: "Denial of Service attacks were first used to "have fun", get some kind of revenge from system operators or make complex attacks possible, such as blind spoofing on services" [9, с. 5].

Терміни-словосполучення в англійській мові $\epsilon$ ланцюжком слів та іноді складаються більш ніж із двох слів. Найбільш поширеними структурами тут $є$ поєднання іменника із прикметником (software, Random Access Memory), іменника 3 іменником в непрямому відмінку (memory capacity). Головним елементом у ній є останнє слово, а означальним - передостаннє слово, словосполучення або складовий термін. За досить частого вживання такі терміни-словосполучення замінюються абревіатурою, яка згодом може входити до складу іншого складного терміна. Так, Message Handling System нині частіше позначається абревіатурою $M H S$.

А. Коваленко виділяє три типи термінів-словосполучень:

- терміни-словосполучення - терміни, компонентами яких є самостійні слова, які можуть уживатися окремо і які зберігають своє значення: link (Adaptable links), unit (Allocation unit), program (Background program);

- терміни-словосполучення, у яких один iз компонентів - технічний термін, а інший - слово загальновживаної лексики. Компонентами такого типу можуть бути два іменники, іменник і прикметник. Цей спосіб утворення науково-технічних термінів більш продуктивний, ніж перший, де два компоненти є самостійними термінами: back coupling, bad register, character spacing, default entry, draft mode;

- терміни-словосполучення, обидва компоненти яких являють собою слова загальновживаної лексики і тільки сполучення цих слів є терміном. Такий спосіб утворення науково-технічних термінів непродуктивний: line wire, burst speed, 
fire button, address map, flat liquid crystal device (LCD) display, letter-quality printing [10, c. 258].

3 погляду семантики виділяються терміни - вільні словосполучення (graphic chart) i стійкі (зокрема, фразеологічні) словосполучення (World Wide Web, system administrator).

В англійській комп'ютерній термінології є велика кількість термінів, що складаються 3 декількох компонентів. Наприклад: read-write head for magnetic tape unit; dynamic pulse storage unit. Такі багатокомпонентні терміни, за твердженням лінгвістів, належать до двох типів: нерозкладені терміни-словосполучення та розкладені терміни-словосполучення.

Також варто зазначити, що характерними явищами у формальній структурі термінів є усічення однослівних термінів (new - newbie - newcomer) i скорочення (абревіація) багатослівних термінів (RAM - Random Access Memory). Спостерігається безліч видів абревіатур: літерні (PDF - Portable Document Format), звукові (PES - programmable electronic system), складові (modem - modulator demomodulator), окрім того, поєднання абревіатур зі словами (FTP-client, де FTP - File Transfer Protocol).

Основною словотворчою моделлю утворення англомовних комп'ютерних термінів є афіксація. Для створення афіксальних новоутворень використовуються як традиційні афікси зі сталими значеннями (ungoogleable), так і афікси, які мають спеціальне значення: -itis (Googleitis), що позначає назви хвороб.

У низці англійських термінів приєднання афіксів відбувається в поєднанні із семантичними процесами (розширення значення, метафоризація): gesturing, fuzzification, gutter .

Особливої уваги потребує словотвірна парадигма термінів, утворених із застосуванням компонента -ware, у функції лексичного компонента дана одиниця застосовувалась для визначення сукупності певного типу продуктів/предметів об'єктивної дійсності, наприклад: hardware, software, silverware, glassware, ovenware.

Компонент -ware набуває значення: «комп’ютеризований засіб /режим збереження та постачання інформації». Наприклад: spyware, shovelware, freeware.

Серед префіксів найбільшою частотністю характеризується формант re- зі значенням повторної дії (наприклад, recopy, recreate, reformat). Префікси cyber- та $e$ - $\epsilon$ інтернаціональними для комп'ютерної термінології, їхня продуктивність висока i має тенденцію до зростання. Окрім загальновживаного $e$-mail, існують такі терміни із префіксом e-: e-book, e-cash, e-form.

Користувачі мережі Інтернет використовують формант net.- як префікс, приєднуючи його практично до будь-якої основи. Наприклад, професі- оналізми: net.newcomer, net.session; жаргонізми: net.lurker, net.god, net.goddess, net.police, net.cops.

Серед префіксів передусім відзначимо також елемент cyber-. Слово cyberspace стало зразком для незчисленної кількості «кіберслів». Іншими прикладами є cyberculture та cyberethics.

Для утворення комп'ютерних термінів в англійській мові активно використовуються префікси латинського походження, характерні для загальнонаукової мови: inter-, super-, mini-, macro-, micro-, auto-, multi-, mega-. Наприклад: autodump: "Despite its location in the window, the Auto Dump checkbox is actually part of the Librarian function" $[11$, c. 36].

Отже, афіксація - це засіб вираження лексичних значень для створення різних слів шляхом додавання морфем / афіксів на початку (префіксація), у середині (інфіксація) або в кінці (суфіксація) слів [12].

Конверсія належить до нелінійних способів словотворення, у процесі конверсії, на відміну від афіксації, слово однієї частини мови переходить в іншу без матеріальної зміни. У термінологічній комп'ютерній лексиці англійської мови досить широко репрезентовані два явища:

- субстантивація: abort (n.), що утворено від abort (v.); click - від дієслова click; autosave - від дієслова save;

- вербалізація: to pirate: "For those who want to pirate, it is simple to copy, modify and redistribute digital media" (Journal of Computers, June, 2009 p.); to spam, to variate.

Беручи до уваги вищесказане, ми можемо відзначити, що конверсія $€$ досить продуктивним засобом створення комп'ютерних термінів англійської мови. Найактивніший процес конверсії перехід іменника в дієслово та навпаки.

Скорочення - це ще один спосіб словотвору, суть якого полягає у відсіканні частини основи, що або збігається зі словом, або являє собою словосполучення, об'єднане загальним змістом. За визначенням «скорочення» $є$ ширшим поняттям, ніж «акронім» або «абревіатура».

Акроніми - це зазвичай абревіатури або короткі дескрипторні фрази, утворені 3 початкових букв важливого терміна у фразі $[13$, с. 1$]$ : ALGOL (Algorithmic Language), LISP (List Processing), FORTRAN (Formula Translation). 3 наведених прикладів виходить, що для утворення акронімів використовуються частини слів, що входять до складу початкових термінологічних груп або корелят. На відміну від акронімів, для утворення абревіатур використовуються лише перші літери слів, що входять до складу початкових термінологічних груп: $F O B, A S A P$.

Скорочення як спосіб утворення нових слів стало дуже поширеним у зв'язку 3 розвитком 
науки та комп’ютерних технологій. Наприклад, назви мов програмування і більшості допоміжних приладів, які використовуються в цій сфері, $\epsilon$ акронімами. Наприклад: BASIC (Beginner's All-purpose Symbolic Instruction Code); $C O B O L$ (Common Business-Oriented Language). Вірогідно, що більша частина користувачів комп'ютерів пов'язує денотат саме зі скороченою назвою і не мають уявлення про прототип.

Окрему групу скорочень становлять абревіатури, що виникли під час листування в інтернеті: $B T W, I C Q, G I G O, L O L$.

Виділяють такі види абревіатур, які є частотними в комп'ютерній підмові, як:

- літерні: SCSI (Small Computer System Interface), $B B S$ (Bulletin Board System), $A M D$ (Advanced Micro Device), $A O L$ (America On-Line), DVD (Digital Video Disk);

- складені: SYNDET (syncronization detect), DISPID (dispatcher identificator); DIGICOM (digital communication);

- початок однієї основи + друга основа: $D$-cache; E-mail, EMS (memory), DOS (disk); hfilez (Hack files) (проф.);

- 3 допоміжними символами: $R x E N$ (receiver enable), Lo-res (low resolution), $R / L$ (read and load), $D T / R$ (data transmit and receive);

- буквено-складені: SAMP (sense amplifier), SOUT (serial output).

Наступний спосіб словотвору - це телескопна номінація. Ї̈̈ можна вважати виявом закону економії мовних засобів. Слова, створені за допомогою цього способу, нагадують складні слова, але створюються із частин («уламків») одного чи двох слів.

Утворення англійських телескопійних слів у сфері інформаційних технологій та інтернету відбувається за одним із двох формальних типів:

а) сполучення двох цілих слів, які репрезентують явище міжслівного накладення. У нашій вибірці воно представлене п'ятьма одиницями javant-garde (Java + avant-garde), dot-commuter (dotcom + commuter), wapplet (WAP + applet), WAPathy (WAP + apathy) Ta splinternet (splinter + internet): "With iPhones, Androids, Kindles, Tablets, TVs and Cars connecting to the Web, a new era is dawning: the Splinternet era, in which the Internet is completely "splintered" and divided into a multitude of devices for content delivery" [14, c. 1].

Написання і вимова двох слів в основі злиття зберігаються. Незначну кількість таких зрощень можна пояснити наявністю небагатьох подібних за формою слів, які можуть залишитися незмінними в телескопійному слові;

б) сполучення одного цілого слова із фрагментом іншого, у результаті чого утворюються «часткові» телескопізми такими способами, як:
1) сполучення цілого першого слова 3 кінцевим фрагментом другого слова;

2) сполучення початкового фрагмента першого слова із цілим другим словом.

«Часткові» злиття становлять, за підрахунками, $26 \%$. Коротше слово зберігає свою форму, до нього додається уламок довшого слова. У 9 проаналізованих зрощеннях цілим залишається перше слово, а потім слідує кінцевий уламок другого слова, наприклад: directronic (direct + electronic), hacktivist (hack + activist): "The case of Mafiaboy raises the question of the rhetorical limits of hacktivism, that is, the combination of hacking and activism, performed for political purposes, including service perceived to be in the public good" (The Fibreculture Journal, April, 2006 p.); webisode (web + episode); geeksploitation (geek + exploitation), craplet (crap + applet), marketecture (market + architecture), sexting (sex + texting); ejectrode (eject + electrode); Googleverse (Google + universe); websumer (web + consumer), codenapping (code + kidnapping), blog (web $+\log$ ). Отже, можна зазначити, що телескопія $\epsilon$ досить поширеним способом утворення термінів комп'ютерної сфери англійської мови, до того ж поширені поєднання двох цілих слів-термінів, двох фрагментів, або поєднання слова та фрагмента слова.

У результаті проведеного аналізу різних способів творення англомовних термінів комп'ютерної сфери ми дійшли висновку, що продуктивними способами творення термінів комп'ютерної сфери $\epsilon$ класичні способи: афіксація, абревіація, конверсія та складання слів, що наглядно було продемонстровано у статті прикладами з різноманітних комп'ютерних журналів, книжок та інтернет-сайтів. Також поширена телескопна номінація. Що стосується термінів-словосполучень, то серед таких найбільш широковживаними структурами $\epsilon$ поєднання іменника із прикметником. Існують терміни-словосполучення, компонентами яких $€$ самостійні слова, які можуть уживатися окремо і які зберігають своє значення, терміни-словосполучення, у яких один із компонентів -технічний термін, а другий - слово загальновживаної лексики, терміни-словосполучення, обидва компоненти яких являють собою слова загальновживаної лексики, тільки сполучення цих слів є терміном.

\section{ЛIТЕРАТУРА}

1. Cabre M.T. Theories of terminology: Their description, prescription and explanation. URL: https://termcoord.files.wordpress.com/2012/03/ theories-of-terminology-en.pdf.

2. Leonardi N. Terminology as a system of knowledge representation: an overview. URL: https:// core.ac.uk/download/pdf/55270623.pdf. 
3. Виноградов В. Русский язык (грамматическое учение о слове). Москва : Учпедгиз, 1947. $784 \mathrm{c}$.

4. Faber P.B. The Cognitive Shift in Termynology and Specialized Translation. URL: https:// www.academia.edu/1376330/The_cognitive_shift_ in_terminology_and_specialized_translation.

5. Реформатский А. Что такое термин и терминология. Москва : Наука, 1959. 140 с.

6. Глушко М. Функциональный стиль общественного языка и методы его исследования. Москва : Слово, 1974. 252 с.

7. Дуда О. До питання про кореляцію загальновживаного слова i терміна. URL: http:/ dspace.wunu.edu.ua/bitstream/316497/25358/1/ До\%20питання\%20про\%20кореляцію\%20 загальновживаного\%20слова\% $20 \mathrm{i} \% 20$ терміна. PDF.

8. Реформатский А. Термин как член лексической системы языка. Проблемы структурной лингвистики. Москва : Наука, 1979. № 4. C. 82-133.

9. Bidou R. Denial of Service Attacks. Paris : Radware, 2005. $20 \mathrm{p}$.

10. Коваленко А. Загальний курс науково-технічного перекладу. Київ : Нова книга, 2001. 290 с.

11. Smith D. Instruments DSI Mopho Sound Editor User Guide. CA. : Soundtower Inc., 2009. 68 p.

12. ValeontisK.,MantzariE.TheLinguisticDimension of Terminology: Principles and Methods of Term Formation. URL: https://www.academia.edu/ 2317735/THE_LINGUISTIC_DIMENSION OF TERMINÖLOGY PRINCIPLES AND METHODS_OF_TERM_FORMATTION Kostas Valeontis Elena Mantzari 2006.

13. Jain A., Cucerzan S., Azzam S. Acronym-Expansion Recognition and Ranking on the Web. URL: http://www.cs.columbia.edu/ alpa/Papers/ieeeiri07.pdf.

14. DRIVECAST. URL: http://www.inrete.it/content/en/PDF/services/drivecast-multimedia/ INRETE-DriveCast-Automotive.pdf.

\section{REFERENCES}

1. Cabre M.T. Theories of terminology Their description, prescription and explanation. URL: https://termcoord.files.wordpress.com/2012/03/ theories-of-terminology-en.pdf.

2. Leonardi N. Terminology as a system of knowledge representation: an overview. URL: https://core.ac.uk/download/pdf/55270623.pdf.
3. Vinogradov V.V. (1947). Russkiy yazyk (grammaticheskoye ucheniye o slove) [Russian language (grammatical teaching about the word)]. Moscow : Uchpedgiz. (in Russian).

4. Faber P.B. (2009). The Cognitive Shift in Terminology and Specialized Translation. URL: https://www.academia.edu/1376330/The cognitive_shift_in_terminology_and_ specialized translation.

5. Reformatskiy A.A. (1959). Chto takoye termin $i$ terminologiya [What is the term and terminology]. Moscow : Nauka (in Russian).

6. Glushko M.M. (1974). Funktsional'nyy stil obshchestvennogo yazyka $i$ metody yego issledovaniya [Functional style of public language and methods of its study]. Moscow : Slovo (in Russian).

7. Duda O. (1998). Do pytannya pro korelyatsiyu zahalnovzhyvanoho slova $i$ termina [On the question of the correlation of common words and terms]. URL: http://dspace.wunu.edu.ua/ bitstream/316497/25358/1/До\%20питання\%20 про\%20кореляцію\%20загальновживаного \%20 слова\% 20i\%20терміна.PDF (in Ukrainian).

8. Reformatskiy A.A. (1979). Termin kak chlen leksicheskoy sistemy yazyka. [The term as a member of the lexical system of the language]. Structural linguistics problems. Moscow : Nauka. № 4. Pp. 82-133 (in Russian)/

9. Bidou R. Denial of Service Attacks. Paris : Radware, 2005.

10. Kovalenko A.Ya. (2001) Zahalnyy kurs naukovotekhnichnoho perekladu [General course of scientific and technical translation]. Kyiv : Nova knyha (in Ukrainian).

11. Smith D. (2009). Instruments DSI Mopho SoundEditor User Guide. CA. : Soundtower Inc.

12. Valeontis K., Mantzari E. (2006). The Linguistic Dimension of Terminology: Principles and Methods of Term Formation. URL: https://www. academia.edu/2317735/THE_LINGUISTIC DIMENSION OF TERMINOLOGY PRINCIPLES AN̄D METHODS OF TERM FORMATION_Kostas_Valeontis_Elena_ Mantzari_2006.

13. Jain A., Cucerzan S., Azzam S. (2007). AcronymExpansion Recognition and Ranking on the Web. URL: http://www.cs.columbia.edu/ alpa/Papers/ ieee-iri07.pdf.

14. DRIVECAST. URL: http://www.inrete.it/ content/en/PDF/services/drivecast-multimedia/ INRETE-DriveCast-Automotive.pdf. 